\title{
Employer Sanctions and the Question of Discrimination: The GAO Study in Perspective
}

Vernon M. Briggs, Jr.

Cormell University

The enactment of the Immigration Reform and Control Act of 1986 (IRCA) produced the most extensive legislation in the area of employment law in the United States in two decades (i.e., since the adoption of the Occupational Health and Safety Act of 1970). Its provisions affect every employer and every job seeker since the law went into effect on November 6, 1986. Among its multiple provisions were strictures designed to prohibit employers from hiring illegal immigrants. This action had the effect of repealing the "Texas Proviso" of the Immigration and Nationality Act of 1952 that specifically exempted the employment relationship from constituting any charge of harboring illegal immigrants who were found on an employer's premises.

All employers are required to complete an Employment Eligibility Verification Form (I-9 form) for each new employee. All prospective job holders are required to provide their employers with the documents needed to prove their eligibility for employment and to attest to their eligibility to work by signing the I-9 form. The employers are not responsible for the authenticity of the documents that are presented but they are required to exercise good faith in their examination of these materials. Civil penalties are specified for employers who do not comply with the documentation requirements or who knowingly violate the hiring ban. Escalating fines and criminal penalties are set forth for repeat offenders. Job applicants are subject to fines and imprisonment if they use false documents to secure employment but there are no penalties on those workers who are hired and who are later found to be ineligible to work.

\section{THE ISSUE OF NATIONAL ORIGIN DISCRIMINATION}

The adoption of the employer sanctions system raised fears in a number of quarters that it could introduce a new opportunity for employment discrimination to occur. Hispanic American groups in particular and other concerned persons as well, worried that the sanctions might cause employers to be too cautious in their hiring practices. To protect themselves from 
possible violations, employers might refuse to hire "foreign-looking" applicants or persons who "speak with accents" even if such job applicants were citizens or resident aliens or, in some cases, certain foreigners who are legally eligible to work under certain prescribed circumstances (e.g., foreign students). It is also, of course, possible that employers could use the sanctions as a false pretext to mask a purposeful desire to discriminate against hiring individuals from certain minority groups.

To address these concerns, IRCA strengthened the existing law on discrimination on the basis of national origin as provided by the Civil Rights Act of 1964. IRCA amended the existing Immigration and Nationality Act to also include a prohibition against national origin discrimination. A new Office of the Special Counsel for Immigration-Related Unfair Employment Practices (OSC) was established within the U.S. Department of Justice to hear these types of complaints and to prosecute offenders. Furthermore, the coverage of the prohibition against national origin discrimination under IRCA was written to apply to employers of four to fourteen employeesunlike the coverage for racial, gender, national origin or religious charges of discrimination under the Civil Rights Act which extends only to employers of fifteen or more workers. Workers covered under the Civil Rights Act may not file charges of national origin discrimination with the OSC. They must use the U.S. Equal Employment Opportunity Commission (EEOC).

\section{THE ISSUE OF CITIZENSHIP DISCRIMINATION}

The politics associated with the adoption of IRCA-linked employer sanctions with four separate amnesty programs that would permit many of the illegal immigrants in the country at that time to adjust their status to become resident aliens and, after the normal five year waiting period, to become naturalized citizens if they so desire. The amnesty provisions were by far the most controversial sections of the new law. In the final floor debate on IRCA in the House of Representatives, an amendment to delete the amnesty provisions was defeated by a narrow seven-vote margin. Had this move succeeded, the disparate political coalition required to pass IRCA would have collapsed and the bill would have died. Many congressmen who supported amnesty, opposed sanctions and visa versa.

The relationship of amnesty to the topic of employment discrimination is complicated but it is crucial to understand. Opponents to amnesty strongly felt that such action would reward law breakers and punish law abiders. Those persons who had unlawfully entered the United States without inspection or who overstayed their visas by remaining in the country after their visas had expired were being given the opportunity to become citizens. On the other hand, prospective immigrants who respected U.S. law by remaining in their countries while applying through the legal channels to 
immigrate face the certain prospect of lengthy delays (due to the extensive backlog in all admission categories) or the likely denial of eligibility under the existing admission preferences (which provide access only to those who have a family relative who is a U.S. citizen or resident alien or to those who have specific job occupational skills that are in short supply). To the many opponents of amnesty, this situation seemed patently unfair.

Because of the strength of this opposition, the supporters of the amnesty concept feared that a significant number of employers might manifest their disdain for amnesty recipients by refusing to hire them while they were in the mandatory status of being resident aliens. In a phrase, they could be discriminated against in their efforts to become employed. Such discrimination was perfectly legal prior to IRCA as there was no existing ban on discrimination on the basis of alienage or citizenship (i.e., resident aliens are not citizens despite the fact that they may legally be employed). The potential harm from citizenship discrimination, of course, could conceivably extend far beyond the several million persons who availed themselves of the benefits of IRCA's amnesty provisions. It could engulf the several million other resident aliens who live and work in the United States, who entered the country legally or as refugees and who are required to remain in the status of permanent resident aliens for at least five years. Many permanent resident aliens never go through the formal naturalization proceedings. They seek only to work in the United States while retaining their foreign citizenships in the event that they someday decide to return to their homelands.

To address these concerns, IRCA introduced a new civil rights protection. It prohibits discrimination on the basis of citizenship by any employer of more than three workers. IRCA is the only federal law to ban citizenship discrimination. An interesting feature of the new provision, however, is that it specifically states that employers may always give hiring preference to a citizen job applicant if the citizen and noncitizen applicants are viewed as being equally qualified. Such absolute preferences for one group relative to another are not available under the Civil Rights Act. The protection against citizenship discrimination applies to the public as well as to the private sector. But in the public sector an important exception is made that greatly limits its scope. Namely, in government employment, certain jobs may be designated by law, regulation, executive order, or government contract to be filled only by citizens. There are many such restrictions; therefore, both the federal and state levels of government legally remain in effect (Briggs, 1984:Ch. 4).

\section{THE REQUIREMENT TO ASSESS POSSIBLE DISCRIMINATORY INFLUENCES}

Controversy swirled around the possible discriminatory effects of employer sanctions throughout the entire time that immigration reform was pending 
before Congress. In 1982, when Congress first began to consider the topic as part of a comprehensive immigration reform package, Representative Frank (D-MA) sought to have an antidiscrimination amendment incorporated in the legislation that emanated from the House of Representatives. He was successful on each occasion over the next four years that a bill reached the House floor. In the final debate on IRCA in the House on October 9, 1986, the Frank Amendment survived a motion to delete its provisions by a vote of 140 to 260 .

In the Senate, however, the need for such protections was consistently resisted. Senator Simpson (R-WY), a coauthor of IRCA, opposed the inclusion of such language. He indicated that the Frank Amendment was one of the most "troublesome" issues on which the Senate had ultimately to accede in the Congressional conference bill that reconciled differences between the House and Senate versions of IRCA (Montweiler, 1987:50-51). Simpson and other legislators not only questioned the need for such provisions but they also feared that the provisions could become yet a new way to harass employers. Despite last ditch efforts to have it deleted, it became apparent that inclusion of these provisions was "quite necessary for final passage" (Montweiler, 1987:51).

In signing IRCA into law, however, President Ronald Reagan took the highly unusual step of simultaneously issuing a detailed statement that set forth the Administrations's interpretation of the antidiscrimination provisions of the new law. It stated that the standard of proof, that aggrieved individuals had to bring to the Office of the Special Counsel, would require individual complainants to establish "discriminatory intent" as opposed to "disparate impact" as permitted under the Civil Rights Act. It also stated that attorney fees would be assessed in all cases where claims did not have "a reasonable foundation in law or in fact" as well as in those cases "found to be vexatious or frivolous" (Montweiler, 1987:51). Thus, without belaboring the point, it is fair to say that the issue of the possible discriminatory effects of employer sanctions was one of the most contentious issues in the entire immigration reform drive.

As it would take experience before it would be known if there was actual need to fear such consequences, IRCA contained a requirement that the Comptroller General of the U.S. General Accounting Office (GAO) study the implementation of the employer sanctions requirement. The study was to isolate any "new" or "increased" discrimination that might be "solely" attributable to the implementation of the sanctions. The mandate was to study national origin discrimination and also citizenship discrimination if such actions have the purpose or effect of discriminating on the basis of national origin. Interim reports were specified with a final report due after three and one half years of the enactment of IRCA. The final report was directed to answer three questions: 1) are the sanctions an unfair burden on 
employers; 2) has the system of sanctions been satisfactorily carried out; and 3) have the sanctions resulted in the creation of a pattern of discrimination against eligible workers?

Depending on the findings of the final report a potential sunset i.e., repeal) provision for the entire sanctions system was written into the law. If the GAO answered the third question in the affirmative (i.e., that sanctions have resulted in a pattern of discrimination), the mere passage of a resolution within 30 days of the issuance of the report by both houses of Congress approving the findings would automatically repeal the entire employer sanctions system of IRCA. Hence, there was an unusual air of anticipation surrounding the release of this particular GAO document.

\section{THE ISSUANCE OF THE REPORT AND ITS PRINCIPAL FINDINGS}

On March 29, 1990, the GAO issued its report (U.S. General Accounting Office, 1990). In answer to the first of the mandated questions, GAO found that the verification requirements of IRCA had not unnecessarily burdened employers and that the sanctions were serving to reduce the magnitude of illegal immigration which was the ultimate goal of the legislation. With respect to the second question, it found that the government agencies responsible for implementing the sanctions program (i.e., U.S. Immigration and Naturalization Service [INS] and the U.S. Department of Labor [DOL]) have "satisfactorily" carried out their duties to educate employers and to identify and fine violators. As for the third question, the report found that national origin discrimination resulting from IRCA "while not pervasive, does exist at levels that amount to more than 'just a few isolated cases' and constitutes a "serious pattern of discrimination"” (U.S. General Accounting Office, 1990:5). Accordingly, the report did "pull the trigger" that provided Congress with the option to repeal the sanctions program by resolution within 30 days. Congress could also, of course, choose to leave the sanctions system alone or to amend IRCA in order to reduce the magnitude of IRCA-related discrimination.

\section{THE PROCESS FOR MEASURING IRCA-RELATED DISCRIMINATION}

There is no issue more difficult to measure in a free labor market than the effects of employment discrimination (Marshall and Briggs, 1989:Ch.17). No employer is obligated to hire any particular job seeker; no job seeker is required to work for any particular employer. Distinguishing between the normal ways in which an employer culls the available labor pool to find the most qualified labor force from ways in which illegal acts of discrimination maybias outcome decisions is no simple feat (Doeringer and Piore, 1971:Ch. 
7). It is important, therefore, to examine how GAO elected to conduct its mandated study as a prelude to assessing the confidence of its findings.

GAO used six different methods to ascertain the information it needed to render a conclusion on the relationship of IRCA to any ensuing discriminatory pattern. Briefly stated, they consisted of 1) a stratified random sample survey of 9,491 employers nationwide to determine how hiring practices were affected by the advent of employer sanctions; 2) a "hiring audit" of randomly selected employers in two cities (Chicago and San Diego) to see how specific job applicants were treated; 3) a worker survey of 300 judgmentally-selected job applicants in five cities that have high concentrations of immigrants in their populations to compare the hiring experiences of "foreign-sounding applicants" with those of "nonforeign-sounding applicants"; 4) a time series analysis of the number of national origin discrimination charges received by the EEOC from 1979 to 1989 to see if there had been any substantial increase in complaints; 5 ) a review of the nature of the discrimination charges received by the newly created OSC from May 1988 to May 1989; and 6) an analysis of state employment service data in Illinois, Florida and Texas to compare the job placement experiences of non-Hispanic whites, blacks and Hispanics.

Although GAO did not assign any weights to the various sources of information it collected, it is clear from the disproportionate discussion in the report that two of the data sources were particularly important to the final determination of the presence of discriminatory impact. These were the employer survey and the "hiring audit."

\section{THE NATURE OF THE DISCRIMINATORY FINDINGS}

With regard to the actual findings, the responses to the employer survey revealed that 19 percent of the surveyed employers introduced discriminatory hiring practices because of the law. Of these, 10 percent of the employers adopted employment practices that discriminated on the basis of a person's "foreign appearance or accent" (i.e., national origin discrimination) and 9 percent initiated employment practices that discriminated on the basis of alienage (i.e., citizenship discrimination).

To be specific, the new hiring practices that had the effect of causing national origin discrimination were those where employers adopted policies to 1) examine documents selectively of only those current employees who had foreign appearances or accents; 2) refrain from hiring job applicants who had foreign appearances or accents; 3) refuse to hire persons who provided Puerto Rican birth certificates; 4) require completed I-9 forms for only some newly hired persons but not others; and 5) use foreign appearance or foreign accent as a precondition to examining documents before making any decision about possibly hiring a job applicant. These discrimi- 
natory employer practices were found to exist most often in cities with high percentages of Asians and Hispanics in their populations. There was, however, no particular pattern found in the incidence of such practices between small-, medium- or large-sized employers. The discriminatory hiring practices that had the effect of causing citizenship origin discrimination consisted of new policies that were implemented to hire only persons born in the United States or to refrain from hiring persons who have only temporary work eligibility.

As for the "hiring audit," GAO contracted with the Urban Institute of Washington, D.C. to have 16 college students apply for jobs in Chicago and San Diego. Called "testers," all were men between 16 and 24 years of age. They were divided into eight pairs. Each pair of testers was "matched as closely as possible on 1) education, 2) work experience and 3) oral communication skills" (U.S. General Accounting Office, 1990:30). The biographies of the applicants were sometimes altered to make them appear as nearly equally qualified as possible. The Urban Institute staff coached the applicants in training sessions to give similar answers to hypothetical questions that an employer might ask. The only purposeful difference between the two members of each pair was that one tester was foreign-looking and foreign-sounding and the other was not. That is to say, one was Hispanic; one was an Anglo (i.e., a non-Hispanic white). GAO admitted that employer decisions as to which specific person was offered a job and which was not could still be related to some characteristic that is not related to the national origin of an applicant. Nonetheless, it felt that, if an aggregate pattern of differential treatment of Hispanic applicants emerged, it would be an indication of national origin discrimination.

A total of 360 employers were audited by these pairs of fictitious job applicants. The applicants were responding to want-ads placed in local newspapers. Generally speaking, they were for low wage, entry level jobs. Three outcomes were compared for each employer: the job application stage, offers for an interview, and the actual receipt of a job offer. In over a majority of the cases $(58 \%)$, there was no discernible difference between the experiences of the members of each pair. Of the remainder, however, 31 percent of the Hispanic interviewees encountered unfavorable treatment while 11 percent of the Anglo interviewees were treated unfavorably. Thus, GAO found that Hispanics were "three times as likely to encounter unfavorable treatment" as Anglos and concluded on this basis that "the hiring audit results show a high level of national origin discrimination" (U.S. General Accounting Office, 1990:47). GAO admits that it is "unclear" why 11 percent of the Anglo interviewees encountered unfavorable treatment under such circumstances. 
As for the other sources of information, the analysis of charges of discrimination filed with the OSC revealed that about one fourth of those reviewed pertained to some aspect of the employer sanctions provisions. The most prevalent allegation involved discrimination by employers who refused to accept certain documents used to verify worker eligibility. Likewise, the survey of 300 job applicants in five cities with high immigrant populations revealed a pattern of differential employee verification experiences applied to foreign-sounding persons versus nonforeign-sounding persons. The persons with foreign accents were more likely to be asked to show documents and not be offered the job; to be asked for eligibility documents during the job interview; or to be asked to complete an I-9 form before being hired than were persons without accents. Interestingly, however, the foreignsounding persons were much more likely to have been actually offered a job $(69 \%)$ than were the nonforeign-sounding persons $(40 \%)$. The explanation for this seeming paradox is that the pools from which interviewees were chosen were not comparable. Hence, GAO could not draw any interpretative conclusion about any discriminatory behavior as to who would be more likely to be actually hired based on this survey. As for the other two measures that were reviewed, the study of placement rates by state employment services and a time series comparison of national origin discrimination charges filed with the EEOC from 1979 to 1989, did not show any evidence of IRCA-related discrimination.

\section{EXPLANATIONS FOR THE FINDINGS}

The GAO offered three explanations for the "widespread pattern of discrimination" that it found to have been caused by employer sanctions: many employers lacked an adequate understanding of the major provisions of IRCA, were uncertain about the proper means to determine worker eligibility, and were confused about what to do if they suspected that the documents they were presented with were counterfeit or fraudulent.

The way to overcome employer ignorance of the terms of the law is through continual educational efforts by INS and DOL. GAO recommended that their efforts be expanded. As for the confusion over the means to determine worker eligibility, it stemmed from the fact that seventeen different documents can be used to establish eligibility. Several of these approved documents are uncommon so it is not surprising that many employers would not accept them. The employers who responded to the employer survey strongly favored a reduction in the number of such documents and GAO concurred. As for the issue of counterfeit and fraudulent documents, the verification requirements of IRCA requires that employers judge the validity of the documents that are presented. Thus, because of the multiplicity of documents that can be used and the common 
knowledge that fake identification is readily available, some employers preferred to "err on the safe side" and decided not to hire foreign-looking or foreign-sounding job applicants. Thus, it was not so much a case of malevolence by employers as it was ignorance and fear that led to the pattern of IRCA-related discrimination found by GAO.

There is, of course, also the possibility that the GAO study itself was faulty in its measurement of discriminatory effects. Most of the various information in the GAO report revealed errors of process or misunderstanding over what was required. The employer responses were, understandably, largely defensive actions or overreactions in the face of uncertainty and confusion about what to do. There were few indications of purposeful actions to use IRCA as an instrument to camouflage discriminatory intent. The lone exception to this conclusion, however, was the data provided by the direct "hiring audit." Here there seemed to be some evidence-although not overwhelming — of differential treatment based directly on national origin.

The validity of the discriminatory findings of the hiring audit is based entirely on the assumption that the two job applicants (one Hispanic and one Anglo) were indeed equal in every important respect other than their obvious ethnic differences. If the members of each team could notbe perceived as being closely matched, any finding pertaining to discrimination is open to question. In fact, GAO acknowledges that it was not possible to control for the "psychological traits" of the members of each team that may have affected an employer's hiring decision which may have had nothing to do with ethnicity itself (U.S. General Accounting Office, 1990:47). But even more serious complaints have been made by Peter Skerry of the American Enterprise Institute (Skerry, 1990:A-12). He requested and was given permission to view the training tapes of the matched pairs of interviewees. Afterward, he stated:

I viewed a videotape in which the 16 individual testers introduced themselves and described their educational backgrounds. I was struck by the number of instances in which the Anglo testers attended more selective universities and displayed more self-assurance than their Hispanic counterparts. Indeed, the Anglos generally appeared to have a social class advantage over the Hispanics which would explain much of the "discrimination" encountered by the latter (Skerry, 1990:A-12).

Thus, the data source that provided the most direct implication of the existence of a pattern of national origin discrimination has been called into serious question.

\section{POLICY IMPLICATIONS}

As the 30-day period in which Congress could have voted to repeal the sanctions program has passed without any action taken, the remaining 
options are to do nothing or to initiate legislative actions to mitigate the opportunities for discrimination to occur. As the GAO report made serious charges and-despite criticisms over its methodologies-it does represent the most impartial and the most comprehensive study yet conducted on the effects of IRCA on employer hiring practices, it seems clear that prevailing policy changes are needed. Indeed, the GAO report reinforces the similar findings of less ambitious state studies conducted by the California Fair Employment and Housing Commission, the New York Interagency Task Force on Immigration Affairs, and the Arizona Civil Rights Advisory Board (for summaries of these reports, see, U.S. General Accounting Office, 1990:84-86). The common thread in these state studies was that IRCA had caused employers to refuse to accept or to be uncertain about the validity of certain work eligibility documents which they were presented.

In this vein, the call by GAO for a continuation of educational efforts by INS and DOL of employers is absolutely necessary. Likewise, the recommendations for DOL to reinspect employers who have been found to have hired illegal immigrants in violation of IRCA's provisions and for efforts to develop an automated sanctions information system to monitor the program are definitely in order. GAO also suggested that Congress act to reduce the number of work eligibility documents and to make those documents that are acceptable more counterfeit proof and less vulnerable to fraudulent use. Certainly, these suggestions should be taken seriously.

There is also another loophole in IRCA that, if closed, would enhance the effectiveness of the employer sanctions program itself. It was not discussed by GAO but it warrants consideration; namely, thought should be given to the imposition of fines and/or criminal penalties against the illegal aliens themselves who are found to be employed despite the existence of the sanctions system. As Barry and Carmel Chiswick have observed, "any attempt to enforce the immigration laws with virtually no cost to the law breaker is destined to perpetuate the revolving door" (Chiswick and Chiswick, 1985:A-20). Such penalties would reinforce an impression of commitment by the nation to the principle of employer sanctions. It might also contribute to a reduction in the flow of illegal aliens.

THE OMITTED ISSUES: PROIMMIGRATION DISCRIMINATION

The topic of discrimination and immigration policy has another dimension that has yet to be examined. Its influence is equally as pernicious as those concerns raised in the GAO report. Namely, the systematic discrimination by employers in favor of immigrants-legal or illegal-to the detriment of citizen workers. This discrimination usually involves decisions by employers who are of a particular ethnic background to hire only immigrants who are 
of the same ethnic background. The effect, of course, is to deny opportunities for citizens, resident aliens, and other persons eligible to work from having the opportunity to be employed. As the number of immigrants continues to rise in both absolute and relative terms, the collective consequences of such employer discrimination mount. This is especially the situation in many major urban labor markets.

It is to be recalled that GAO could offer no explanation for the fact that 11 percent of Anglo interviewees in the hiring audit encountered unfavorable treatment that could be related to IRCA requirements. One plausible explanation is that the Anglos were discriminated against by employers because they were citizens or were not of a particular national origin. All of the interviews took place in two urban areas with large foreign born populations. All of the interviewees were applying for entry level and relatively unskilled jobs. It is quite possible that the Anglos encountered ethnic employers who would not hire Anglos (e.g., Hispanic or Asian employers who only wanted to hire Hispanic or Asian workers). This may also explain the reason why, in the study used by GAO to determine the experiences of foreign-sounding persons, these persons had a considerably higher job placement than did the nonforeign-sounding job seekers.

Because the topic of proimmigrant discrimination in contemporary times has never been carefully researched, the indications of the presence of such bias are fragmentary. Nonetheless, there are strong indications of its existence. In a very proimmigrant study of immigration in New York City, Elizabeth Bogen noted the phenomenon when she candidly wrote: "there are tens of thousands of jobs in New York City for which the native born are not candidates" (Bogen, 1987:91). The reasons she cites are that "ethnic hiring networks and the proliferation of immigrant-owned small businesses in the city have cut off open-market competition for jobs" (Bogen, 1987:91). Quite perceptively, she strongly suggests that the blatant "discrimination against native workers is a matter for future monitoring." Given the mounting racial tension in many urban communities between citizens (especially African Americans) and recent immigrants, the need for such research on this subject is long overdue. Likewise, research in those rural labor markets where immigrant workers have become a significant factor-e.g., in the agriculture industry of the Southwest-has also noted the widespread use of ethnic networking which dominates the hiring process (Mines and Martin, 1984:144). The negative effect on the employment of native born workers for these rural jobs is the same in its results as it is in urban labor markets. The concept of networking is highly praised by many scholars who study the current immigrant experience. But what is overlooked in these studies is that most of these practices-especially those of ethnic employ- 
ers-are absolutely illegal. What is the difference between "ethnic networking" which is often lauded and "the old boy system" which is roundly condemned by antidiscrimination advocates?

In earlier waves of immigration, networking served to aid in the assimilation process of immigrants. But those immigrants entered the United States prior to the passage of the Civil Rights Act of 1964. Times in the United States have changed-hopefully for the better. Today any employment practice that purposely excludes opportunities for native born workers is illegal conduct and it should be stopped. Unfortunately, the contemporary politics associated with immigration policy at the federal, state, and local level has been reluctant to address this issue. The GAO report-which has nothing to say about this issue at all-may have opened a door of opportunity which will allow all aspects of the discrimination issue, as it relates to the presence of immigrants in the labor market, to be addressed.

\section{CONCLUDING OBSERVATIONS}

The GAO study has made a major contribution to efforts to assure that fair play in the labor market occurs. Its findings, while open to debate as to the actual magnitude, do show that there is a problem with the existing employer sanctions system. There have been unintended adverse consequences that go beyond being mere technical violations. There is a necessity for greater clarity for employers who are on the front line of the hiring process. Fewer and more secure documents that cannot be counterfeited or fraudulently used are mandatory steps. Perhaps the positive implications of a single national identification system should be explored once again-despite the clear prohibition against such a system currently in IRCA. Likewise, the use of fines for illegal aliens who have somehow defied the employer sanctions should also be considered.

In any event, the nation is indebted to Congressman Frank for his perseverance to have had the antidiscrimination provisions built into IRCA. It is to be hoped that if Congress elects to amend IRCA that the employer sanctions system will not be weakened, but rather that it will be made simpler for employers to understand. It would also help if Congress would balance its concern for stopping discrimination against foreign born persons eligible to work by native born employers with an equal interest in assuring that there will be no discrimination against native born persons by foreign born employers.

\section{REFERENCES}

Bogen, E.

1987 Immigration in New York. New York: Praeger Publishers. 
Briggs, V. M.

1984 Immigration Policy and the American Labor Force. Baltimore: The Johns Hopkins University Press.

Chiswick, B. R. and C. U. Chiswick

1985 “'Illegals' Should Pay for Breaking the Law,” Los Angeles Times, October 9, 1985.

Doeringer, P. B. and M. J. Piore

1971 Internal Labor Markets and Manpower Analysis. Lexington, Massachusetts: D. C. Heath and Company.

Marshall, R. and V. M. Briggs

1989 Labor Economics: Theory, Institutions and Public Policy. Homewood, Illinois: Richard D. Irwin, Inc.

Mines, R. and P. Martin

1984 "Immigrant Workers and the California Citrus Industry." Industrial Relations, 24(1):139_ 149. Spring.

Montweiler, N. H.

1987 The Immigration Reform Law of 1986: Analysis, Text, and History. Washington, D.C.: Bureau of National Affairs, Inc.

Skerry, P.

1990 "Hispanic Job Discrimination Exaggerated," Wall Street Journal, April 27:A-12.

U.S. General Accounting Office

1990 Immigration Reform: Employer Sanctions and the Question of Discrimination. Washington, D.C.: U.S. Government Printing Office. 